\title{
DISKRIMINASI GENDER DALAM NOVEL ENTROK KARYA OKKY MADASARI: KAJIAN FEMINISME
}

\author{
Ririn Setyorini \\ Pendidikan Bahasa dan Sastra Indonesia, Fakultas Ilmu Pendidikan \\ Universitas Peradaban Bumiayu \\ ririnsetyorini91@gmail.com
}

\begin{abstract}
Abstrak
Feminisme adalah gerakan dalam menuntut emansipasi yang memperjuangkan kesetaraan bagi perempuan baik dalam polotik, ekonomi, budaya, ruang pribadi, dan ruang publik. Marni dalam novel Entrok adalah salah satu korban pada zaman orde baru di mana ketidakadilan dan kesetaraan sangat dia rasakan sebagai perempuan. Sebagai wanita Jawa yang penuh dengan diskriminasi gender, Marni ingin bangkit dari keterbatasan tersebut salah satunya dalam hal pekerjaan. Keinginannya tersebut membuat dia harus melawan kodratnya sebagai perempuan hingga menuai cibiran dari masyarakat setempat. Penelitian ini merupakan penelitian deskriptif kualitatif. Data dalam penelitian ini berupa paragraf yang terdapat dalam novel Entrok Karya Okky Madasari dan sumber data novel dan buku acuan yang berkenaan dengan penelitian. Teknik sampling yang digunakan adalah purposive sampling, teknik pengumpulan data dengan teknik baca dan teknik catat. Teknik analisis data dalam penelitian ini dengan analisis isi. Tujuan dari penelitian ini adalah mendeskripsikan bagaimana deskripsi gender yang dialami oleh tokoh Marni dalam novel Entrok karya Okky Madasari. Hasil dari penelitian ini adalah adanya diskriminasi gender yang dialami oleh tokoh Marni yang membuat Marni harus melanggar norma dan kodratnya sebagai perempuan di masa tersebut.
\end{abstract}

Kata kunci: Novel Entrok, Okky Madasari, Diskriminasi, Feminisme

\begin{abstract}
Feminism is a movement of claiming emancipation which struggle with the women's equality in politics, economy, culture, private and public space. Marni, the character in novel Entrok is one of the victims of the New Order (orde baru) where injustice and inequality happened to her. As a Javanese woman with gender discrimination issue, she wants to rise her status up from the gender limitation. Her willingness made her fight against her nature as Javanese woman thus she got scorned by local peoples. This research method is qualitative descriptive. The paragraphs in novel Entrok written by Okky Madasari and also the reference books are the data of this research. Data collected by reading and noting technique and analized with content analysis. The aim of this research is to describe the gender discrimination she had in novel Entrok. The result shows that there is gender discrimination so that Marni had to break the norm and her nature as Javanese woman in that era.
\end{abstract}

Keywords: Novel Entrok, Okky Madasari, Discrimination, Feminism 


\section{PENDAHULUAN}

Karya sastra lahir di tengahtengah masyarakat sebagai hasil imajinasi pengarang serta refleksinya terhadap gejala-gejala sosial di sekitarnya. Meskipun demikian, karya sastra yang diciptakan pengarang kadang-kadang mengandung subjektivitas yang tinggi. Sebuah karya sastra merupakan sebuah kebulatan yang utuh, khas, dan berdiri sendiri.

Chris Barker (2016: 244) mengemukakan bahwa identifikasi diri sebagai jantan atau betina adalah landasan utama bagi identitas diri yang banya diyakini sebagai hasil dari badan dan stribut tertentu. Logika umum mencakup berbagai bentuk rekuksionalisme biologis yang menyatakan bahwa struktur biokimia dan struktur genetis manusia menentukan perilaku laki-laki dan perempuan dengan cara yang pasti dan khas. Laki-laki umumnya diyakini 'secara ilmiah' lebih mendominasi, berorientasi hierarkis dan haus kekuasaan, sementra peempuan dillihat sebagai pemelihara, pengasuh anak, dan berorientasi domestik.

Bicara tentang feminis adalah berbicara tentang perempuan. Feminis menurut Nyoman Kutha Ratna (2013: 226) berasal dari kata femme yang berarti perempuan. Sugihastuti (2002:18) berpendapat bahwa feminisme adalah gerakan persamaan antara laki-laki dan perempuan di segala bidang baik politik, ekonomi, pendidikan, sosial dan kegiatan terorganisasi yang mempertahankan hakhak serta kepentingan perempuan. Sugihastuti juga berpendapat bahwa feminis merupakan ke-sadaran akan penindasan dan pemerasan terhadap perempuan dalam masyarakat, baik di tempat kerja dan rumah tangga. Feminisme berbeda dengan emansipasi, menurut Sofia dan Sugihastuti (dalam Sugihastuti dan Itsna Hadi Saptiawan,
2007: 95) emansipasi lebih menekankan pada partisipasi perempuan dalam pembangunan tanpa memper-soalkan hak serta kepentingan mereka yang dinilai tidak adil, sedangkan feminisme memandang perempuan memiliki aktivitas dan inisiatif sendiri untuk mempergukan hak dan ke-pentingan tersebut dalam berbagai gerakan. Feminisme sendiri merupakan kajian sosial yang melibatkan kelompok-kelompok perempuan yang tertindas, utamanya tertindas oleh budaya partiarkhi. Feminisme berupa gerakan kaum perempuan untuk memperoleh otonomi atau kebebasan untuk menentukan dirinya sendiri. Berupa gerakan emansipasi perempuan, yaitu proses pelepasan diri dan kedudukan sosial ekonomi yang rendah, yang mengekang untuk maju. Menurut Philips Bob Cock Goefe feminisme ialah teori tentang persamaan antara laki-laki dan perempuan di bidang politik, ekonomi, dan sosial; atau kegiatan terorganisasi yang memperjuang-kan hak-hak serta kepentingan perempuan (Sugihastuti, 2002 : 18).

Pada dasarnya tujuan dari feminisme adalah menyamakan kedudukan atau derajat pe-rempuan dan lakilaki. Feminisme memperjuangkan kemanusiaan kaum perempuan, memperjuangkan perempuan sebagai manusia merdeka secara utuh. Nilai-nilai yang terkandung dalam feminisme yaitu pengetahuan dan pengalaman personal, misalnya antara perempuan berkulit putih dan hitam tentu saja akan berbeda.

Feminis bukan merupakan upaya pemberontakan terhadap laki-laki, bukan upaya melawan pranata sosial, budaya seperti perkawinan, rumah tangga, maupun bidang publik. Kaum perempuan pada intinya tidak mau dinomorduakan, tidak mau dimarginalkan.

Pada awalnya antara pria dan wanita terdapat kesetaraan jender. Pembagian kerja di antara mereka 
dilakukan berdasarkan fungsi biologis (kodrat) masing-masing. Namun dalam per-kembangannya kemudian muncul perbedaan jenis pekerjaan yaitu pekerjaan luar (publik) yang umum dilakukan oleh pria dan pekerjaan dalam/rumah tangga (domestik) yang umumnya dikerjakan oleh wanita.

Pemisahan lingkup kerja yang awalnya hanya digunakan untuk memudahkan sistem pembagian tugas pada akhirnya menjadi semacam kebiasaan yang membudaya. Awalnya perubahan budaya itu terjadi secara wajar-wajar saja. Namun sayangnya dalam proses selanjutnya pandangan manusia atas hak milik diperluas. Bukan hanya hak milik atas barang-barang, tetapi juga hak untuk mengambil segala keputusan dalam hidup. Pada waktu yang sama, terjadilah perampasan hak wanita dalam pengambilan keputusan. Peristiwa perampasan ini menjadi semakin kuat lagi ketika manusia menghargai nilai harta lebih tinggi dari nilai manusia.

Diskriminasi dapat diartikan sebagai sebuah perlakuan terhadap individu secara berbeda dengan didasarkan pada gender, ras, agama, umur, atau karakteristik yang lain. Diskriminasi juga terjadi dalam peran gender. Sebenarnya inti dari diskriminasi adalah perlakuan berbeda. Akibat pelekatan sifat-sifat gender tersebut, timbul masalah ketidakadilan (diskriminasi) gender.

Driskriminasi gender merupakan kondisi tidak adil akibat dari simtem dan struktur sosial di mana baik perempuan dan laki-laki menjadi korban dari sitem tersebut. Berbagai pembedaan peran dan kedudukan antara perempuan dan lakilaki baik secara langsung yang berupa perlakuan maupun sikap dan yang tidak langsung berupa dampak suatu peraturan perundang-undangan maupun kebijakan telah menimbulkan berbagai ketidakadilan yang berakar pada sejarah, adat, norma, ataupun dalam berbagai struktur yang ada dalam masyarakat.

Fakih (2008) mengemukakan secara rinci manifestasi ketidakadilan gender, yaitu: marjinalisasi (peminggiran), sub-ordinasi (penomorduaan), stereotipe, kekerasan (violence), dan beban kerja berlebihan.

Novel Entrok merupakan novel yang mengandung cerita seorang perempuan yang tertindas dan memiliki keterbatasan gerak dalam hidupnya karen dia adalah seorang perempuan. Marni dalam novel Entrok adalah salah satu korban pada zaman orba di mana ketidakadilan dan kesetaraan sangat dia rasakan sebagai perempuan. Sebagai wanita Jawa yang penuh dengan keterbatasan gerak, Marni ingin bangkit dari keterbatasan tersebut salah satunya dalam hal pekerjaan. Keinginannya tersebut membuat dia harus melawan kodratnya sebagai perempuan hingga menuai cibiran dari masyarakat setempat.

Cerita dalam novel Entrok berawal dari seorang Marni yang begitu ingin memiliki entrok untuk menutupi dadanya yang mulai membesar. Marni meminta kepada Si Mboknya, namun hal tersebut tidak dihiraukan oleh Simboknya karena pada masa itu entrok adalah suatu barang mewah yang tidak setiap orang dapat memilikinya. Keinginan Marni tidak dapat dikendalikan, sehingga Marni berusaha mendapatkan apa yang dia inginkan tersebut. Namun, sebagai seorang perempuan, banyaknya keterbatasan yang menjadi kendala dalam memenuhi keinginannya tersebut.

Keinginan Marni yang begitu kuat membua Marni tidak menghiraukan apa yang dikatakan Si Mboknya. Dari satu masalah ke masalah yang lain yang tak dihiraukannya, Marni semakin menjadi dengan keinginan-keinginan Marni yang tak terkendali, yang membuat Marni semakin lupa akan kodratnya sebagai perempuan di masa itu. Marni terus 
berusaha meraih semua mimpi-mimpinya tersebut dengan segala kerja kerasnya.

Dari penjelasan tersebut, tujuan dari penelitian ini adalah mendeskripsikan bagaimana dis-kriminasi gender yang dialami oleh tokoh Marni dalam novel Entrok karya Okky Madasari.

\section{METODE PENELITIAN}

Penelitian ini merupakan penelitian deskriptif kualitatif. Data dalam penelitian ini berupa paragraf yang terdapat dalam novel Entrok Karya Okky Madasari dan sumber data novel dan buku acuan yang berkenaan dengan penelitian. Teknik sampling yang digunakan adalah purposive sampling, teknik pengumpulan data dengan teknik baca dan teknik catat. Teknik analisis data dalam penelitian ini dengan analisis isi dan dengan pendekatan feminisme eksistensialis.

\section{HASIL DAN PEMBAHASAN}

Dalam menganalisis novel Entrok karya Okky Madasari dengan pendekatan feminis ini, penulis mengkaji isi novel tersebut dilihat dari lokalitas tokoh utama atau tokoh perempuan dalam novel tersebut.

\section{Diskriminasi gender tokoh Marni dalam novel Entrok karya Okky Madasari.}

Diskriminasi yang dialami oleh tokoh Marni sebagai seorang perempuan terlihat ketika dirinya begitu ingin mendapatkan uang untuk membeli entrok. Berbagai upaya dia lakukan hingga dia melawan kodratnya sebagai perempuan Jawa untuk dapat memenuhi hasratnya tersebut. Hal tersebut terlihat dalam kutipan-kutipan berikut.

Aku tak bicara soal entrok kepada Simbok. Aku hanya berkata ingin membantunya mengupas singkong, siapa tau bisa dapat uang. Simbok berkata, aku tak akan mendapatkan uang. Kebiasaan di pasar, buruh-buruh perempuan diupahi dengan bahan makanan. Beda dengan kuli laki-laki yang diupahi dengan uang. (hlm. 22)

Kutipan tersebut me-nunjukan ketidakadilan antara perempuan dengan laki-laki, yaitu dalam bekerja seorang perempuan mendapat bayaran hanya bahan makanan/ singkong berbeda dengan seorang laki-laki yang dibayar dengan uang

Aku terdiam setengan kecewa. Tapi aku tetap memaksa ikut ke pasar. Aku bilang pada Simbok, tak apalah kita kupas singkong diupahi singkong. Paling tidak kalu ikut membantu, singkong yang kita bawa pulang bisa semakin banyak. Gaplek yang kita punya bisa makin banyak. Kita bisa makan lebih banyak dan jadi kenyang. Simbok mebiarkan aku ikut ke pasar. Aku berpikir bagaimana caranya menukar upah dengan entrok. (hlm. 23)

Kutipan tersebut menunjuk-an kekecewaan Marni ketika dia ingin ikut bekerja namun tidak diperbolehkan oleh Simboknya. Simbok Marni berpesan bahwa perempuan bekerja di pasar adalah untuk berdagang atau ikut bantu-bantu di pasar seperti mengupas singkong dan tidak akan diupah uang.

Kutimang-timang upahku hari ini, delapan singkong. Simbok mendapat sepuluh singkong. Aku berpikir upah yang didapat Teja, si kuli di pasar, setiap hari. Teja mendapat satu rupiah untuk setiap barang yang diangkatnya. Kalau sehari dia bolak-balik mengangkat sepuluh kali, dia sudah mendapat sepuluh rupiah. Lima hari berkerja, uang Teja cukup untuk membeli satu entrok. Kenapa aku tidak bekerja seperti Teja? (hlm. 33).

Kutipan tersebut menunjukan ketika Marni mulai lelah bekerja mengupas singkong dan hanya mendapatkan singkong. Marni berpikir untuk 
bekerja menjadi kuli seperti Teja agar dia mendapat uang.

Teja terbahak-bahak mendengar permintaanku. Sungguh bukan jawaban seperti itu yang kuinginkan. Aku menunggu agak lama untuk mendapatkan jawaban yang sebenarnya.

"NI, kamu ada-ada saja. Nggak ada perempuan nguli. Nggak ada yang akan kuat. Sudah, perempuan itu kerja yang ringan-ringan aja. Ngupas singkong. (hlm. 34)

Kutipan tersebut menunjukkan lokalitas perempuan bekerja adalah hanya sebagai seorang pengupas singkong. Hal tersebut terlihat ketika Teja yang menertawakan Marni yang ingin bekerja menjadi seorang kuli angkut di pasar.

"Aku kuat, Kang. Biasanya aku juga nggendong tenggok, nggendong goni. Bakul-bakul itu juga banyak yang mengangkat sendiri dagangannya dari rumah ke pasar. Hanya priyayi-priyayi saja yang nggak kuat ngangkat goni."

Kutipan tersebut menunjukan keseriusan Marni dalam mendapatkan uang. Marni rela melawan kodratnya sebagai seorang perempuan dengan bekerja menjadi seorang kuli di pasar.

Waktu kuceritakan ren-canaku pada Simbok, dia angsung menolaknya. "Nduk, semua itu sudah ada jatahnya. Orang kayak kita bagiannya ngoceki telo, nguli itu berat. Sudah jatah orang lain."

"bukan masalah kuat-nggak kuat, Nduk. Ini masalah ilok-ra ilokpantas nggak pantas. Nggak ada perempuan nguli.",

Kutipan tersebut menunjuk-an ketika Simbok Marni menolak anaknya menjadi kuli. Hal tersebut dikarenakan mnjadi kuli adalah sebuah ketidakpantasan bagi perempuan atau dalam bahasa Jawa adalah ora ilok. Dari kutipan tersebut sangat telihat lokalitas perempuan dalam bekerja sangat dibatasi.
Pagi itu kami berangkat ke pasar, tanpa menyinggung rencanaku nguli. Simbok sudah yakin aku tak akan melakukan hal yang ra ilok. Padahal dalam hati aku tetap bertekad akan nguli. Akan kutinggakan Simbok saat dia sibuk mengupas singkong-singkong Nyai Daimah. Aku akan pergi sebentar. Setiap selesai ngangkat barang, aku akan kembali sebentar mengupas singkong. Simbok lalu akan mengira aku kebelet atau bermain dengan anak-anak. (hlm. 35).

Kutipan tersebut menunjukkan ketika Marni ingin sekali mendapatkan uang untuk membeli entrok. Dia berencana untuk menjadi kuli di pasar bersama dengan Teja. Hal tersebut menunjukan perlawanan dari Marni atas lokalitas perempuan Jawa yang hanya boleh bekerja sesuai dengan kodratnya.

Aku tertawa dalam hati saat mendengan nasihat Mbah Noto. Memang benar, di pasar ini tidak ada perempuan yang nguli, pekerjaan berat yang menggunakan tenaga besar. Di pasar ini, buruh perempuan mengerjakan pekerjaan yang halus dan enteng, seperti mengupas singkong, menumbuk adi, atau menumbuk kopi. Tapi coba lihat, begitu buruhburuh perempuan itu sampai di rumah. Mereka harus mengerjakan semua pekerjaan yang ada, mengambil air dari sumber dengan menempuh perjalanan naik-turun. Berat satu jun yang berisi penuh air sama saja dengan satu goni berisi singkong. Tidak ada laki-laki yang mengambil air, katanya itu urusan perempuan. Yang jelas lebih enak nguli daripada ngambil air. (hlm. 37).

Kutipan tersebut menunjukan ketika protes masyarakat mulai terjadi 
ketika melihat Marni yang seorang permpuan harus menjadi kuli di pasar. Hal tersebut merupakan tindakan yang menurut Mbah Noto adalah melawan kodrat sebagai pe-rempuan karena kuli adalah pekerjaan bagi kaum laki-laki.

Aku yang satu-satunya perempuan di antara kuli-kuli langsung merasa wanita itu memanggilku. Inilah kiranya orang yang akan pertama kali memberiku uang (hlm. 38).

Kutipan tersebut menunjuk-an bahwa sudah sangat jelas tidak ada seorang perempuan itu bekerja sebagai kuli di pasar, karena hal tersebut berkaitan dengan ilok-ra ilok yang berarti tidak pantas untuk seorang perempuan bekerja berat seperti kuli.

Aku harus mengambil gaplek belanjaan perempuan itu di tempat Nyai Daimah. Melihatku nguli, Nyai Daimah menyapa setengah mengejek, "Wah, dapat duit ya sekarang”. Sementara Simbok hanya diam, pura-pura tidak tahu (hlm. 38)

Kutipan di atas menunjukan perlakuan dari sekitar Marni yang merendahkannya melihat dia nguli di pasar karena memang pekerjaan yang dia lakukan tidak sewajarnya dilakukan oleh seorang wanita.

Sayangnya tidak ada buruh perempuan di sini, betapapun ingin aku mengupaih mereka dengan uang sebesar buruh lelaki. Upah yang besarnya sama, tidak lebih kecil hanya karna dia perempuan, lebih-lebih hanya diupahi telo. (hlm. 103)

Kutipan tersebut menunjuk-an ketika Marni yang telah sukses ingin sekali menyetarakan upah perempuan dengan upah laki-laki, yaitu sama-sama diupahi uang bukan lagi telo/ singkong.

Kalau Mbah Ibu Bumi Bapa Kuasa mengizinkan, semoga rezekiku dilancarkan, aku punya duit untuk membeli tanah lagi yang kutanami padi dan kacang. Akan aku pekerjakan perempuan-perempuan itu dan kuberi upah tak kurang daripada yang diterima suamisuami mereka. (hlm. 103)

Kutipan di atas menunjukan bahwa perempuan-perempuan pada waktu itu diberi upah yang jauh dari penghasilan para suaminya. Marni berdoa kepada leluhurnya agar dia diberi rezeki untuk membeli tanah agar perempuan dapat pula bekerja di ladang dan mendapat upah uang tak lagi bekerja dan memdapatkan bahan makanan itu-itu saja.

Kutipan-kutipan di atas merupakan sebuah penggambaran dari lokalitas seorang perempuan khususnya dalam bekerja. Perempuan terlalu mendapat batasan yang tentunya kurang adil apabila dilakukan, seperti perempuan hanya mendapat upah bahan makanan bukan diupahi uang seperti yang didapat oleh laki-laki.

\section{SIMPULAN}

Dari kutipan-kutipan di atas dapat disimpulkan bahwa penggambaran diskriminasi gender khususnya dalam bekerja sangatlah terlihat jelas. Pada masa tersebut (orde baru) seorang perempuan khususnya perempuan Jawa dituntut bekerja yang ringan-ringan saja dan hanya mengurusi urusan dapur saja. Pekerjaan berat seperti menjadi kuli yang dilakukan oleh Marni merupakan sesuatu yang melawan kodrat dan tidak pantas untuk dilakukan. Perempuan juga mendapat ketidak adilan dalam mendapatkan upah hasil mereka bekerja. Seorang perempuan bekerja, upah yang mereka dapatkan adalah bahan makanan/ singkong, sedangkan laki-laki mendapatkan uang yang bisa mereka gunakan untuk membeli apa saja. 


\section{DAFTAR PUSTAKA}

Barker, C. (2016). Cltural Studies. Yogyakarta: Kreasi Wacana.

Fakih, M. (2008). Analisis Gender dan Transformasi Sosial. Yogyakarta: Pustaka Pelajar.

Madasari, O. (2010). Entrok. Jakarta: PT Gramedia Pustaka Utama.

Ratna, N. K. (2013). Teori, Metode, dan Telaah Penelitian Sastra. Yogyakarta: Pustaka Pelajar.

Sihite, R. (2007). Perempuan, Kesetaraan, keadilan Suatu
Tinjauan Berwawasan Gender. Jakarta: Raja Grafinda Persada.

Sugihastuti dan Suharto. (2002). Kritik Sastra Feminis Teori dan Aplikasinya. Yogyakarta : Pustaka Pelajar.

Sugihastuti, Saptiawan, I. H. (2007). Gender dan Inferioritas Perempuan (Praktik Kritik Sastra Feminis). Yogyakarta: Pustaka Pelajar.

Winarni, R. (2009). Kajian Sastra. Salatiga: Widya Sari. 